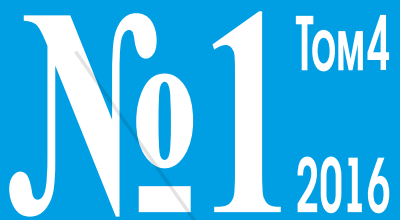

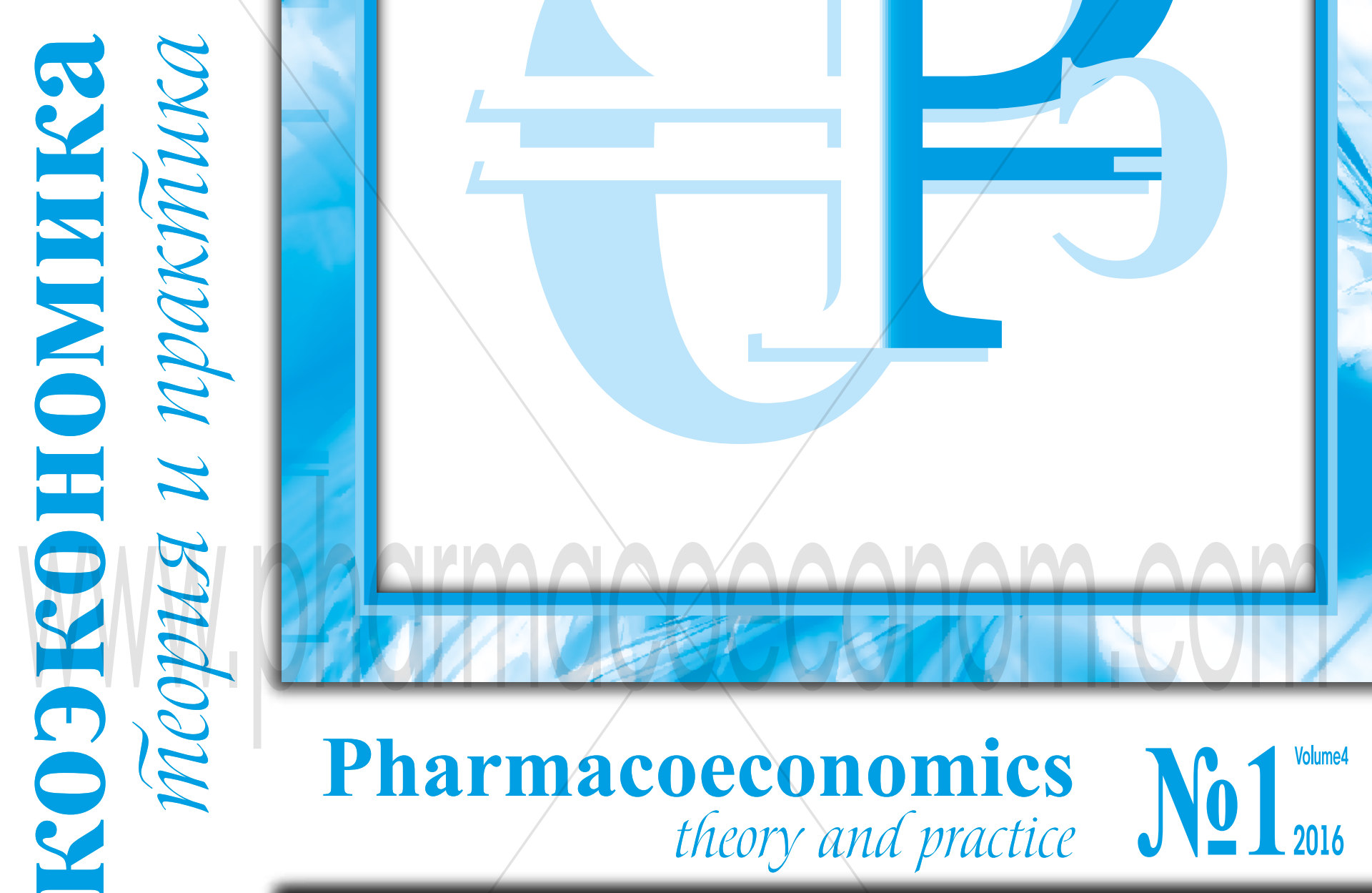

$\square$ МЕТОДОЛОГИЧЕСКИЕ ОСНОВЫ ФАРМАКОЭКОНОМИЧЕСКОГО МОДЕЛИРОВАНИЯ

$\square$ РЕЗУЛЬТАТЫ РОССИЙСКИХ ФАРМАКОЭКОНОМИЧЕСКИХ ИССЛЕДОВАНИЙ

口 МАТЕРИАЛЫ Х НАЦИОНАЛЬНОГО КОНГРЕССА С МЕЖДУНАРОДНЫМ УЧАСТИЕМ «РАЗВИТИЕ ФАРМАКОЭКОНОМИКИ И ФАРМАКОЭПИДЕМИОЛОГИИ В РОССИЙСКОЙ ФЕДЕРАЦИИ» 4-5 апреля 2016 г., г. Нижний Новгород 


\title{
ФАРМАКОЭПИДЕМИОЛОГИЧЕСКИЙ \\ АНАЛИЗ \\ ФАРМАКОТЕРАПИИ ЯЗВЕННОЙ БОЛЕЗНИ ЖЕЛУДКА И 12-ПЕРСТНОЙ КИШКИ ПАЦИЕНТОВ В УСЛОВИЯХ ГАСТРОЭНТЕРОЛОГИЧЕСКОГО ОТДЕЛЕНИЯ Г. САРАТОВА

\author{
PHARMACOEPIDEMIOLOGIC \\ ANALYSIS \\ OF \\ PEPTIC \\ ULCER \\ PHARMACOTHERAPY IN SARATOV GASTROENTEROLOGIC DEPARTMENT
}

\author{
Левитан А.И., Байтман Т.П., Ивличев А.В., Решетько О.В. \\ Levitan A.I., Baytman T.P., Ivlichev A.V., Reshetko O.V.
}

\author{
ГБОУ ВПО Саратовский ГМУ им. В.И. Разумовского Минздрава России, г.Саратов \\ Saratov State Medical University named after V.I. Razumovsky, Saratov
}

\section{очевые слова: противоязвенная терапия, фармакоэпидемиология}

Введение: одной из возможных причин высоких показателей заболеваемости и частоты развития осложнений язвенной болезни (ЯБ) является нерациональная фармакотерапия, поэтому вопрос и проводимом медикаментозном лечении данного заболевания очень актуален.

Цель исследования: провести фармакоэпидемиологический анализ лекарственных средств (ЛС), применяемых для лечения ЯБ у пациентов стационара одной из больниц г. Саратова и оценить адекватность назначаемой терапии с точки зрения ее соответствия современным рекомендациям (Клиническим рекомендациям по диагностике и лечению язвенной болезни 2013 и Рекомендациям по лечению инфекции H. pylori (Маастрихт-IV/ Флоренция).

Материалы и методы: проведено открытое ретроспективное фармакоэпидемиологическое исследование, основанное на анализе историй болезней 49 пациентов с ЯБ, поступивших на стационарное лечение в гастроэнтерологическое отделение больницы г. Саратова с 4 января по 20 апреля 2013 года. На каждый случай заполнялась специально разработанная индивидуальная регистрационная карта. Полученные данные обрабатывались с помощью компьютерной программы Exсеl для Windows XP.

Результаты: проанализировано 49 историй болезни пациентов с ЯБ $82 \%$ - мужчины и 18\% - женщины, средний возраст которых составил

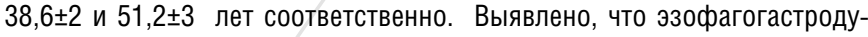
оденоскопия (ЭГДС) + биопсия и цитологическое исследование желудка на наличие Н. pylori проведено у 98\% больных. ЯБ желудка была диагностирована у $21 \%$, а 12-перстной кишки - у 79\% больных. Чувствительность выделенной H.pylori к антигеликобактерным антибактериальным средствам не исследовалась.

Антисекреторная терапия применялась у всех пациентов (100\%), что соответствует современным требованиям. При этом в качестве антисекреторной терапии в виде монотерапии ингибиторы протонной помпы (ИПП) были назначены в 90\% случаев, Н2-гистаминоблокаторы - в 2\%, комби- нация ИПП с Н2-гистаминоблокаторами - в 8\%. Частота назначения антисекреторных препаратов следующая: омепразол в $73 \%$ предписаний, эзомепразол - $21 \%$, рабепразол - 4\%, фамотидин - $10 \%$. ИПП являются препаратами выбора для проведения антисекреторной терапии при ЯБ, а Н2-гистаминоблокаторы по современным рекомендациям могут использоваться только при невозможности применения ИПП или же в комбинации с ними с целью усиления антисекреторного действия. Антациды были использованы в более чем половине случаев (57\%) как один из компонентов терапии ЯБ, что соответствует современным рекомендациям по использованию их для купирования болей и диспепсических жалоб, а в данном исследовании это были основные жалобы больных. Эрадикация H. pylori была рекомендована 87\% пациентов гастроэнтерологического отделения с выявленным Н. pylori-инфицированием (из них $12 \%$ была назначена на стационарном этапе лечения, а $75 \%$ пациентов было рекомендовано проводить эрадикационную терапию на амбулаторном этапе, в связи с поздним получением результатов обследования). $13 \%$ пациентов, инсрицированных H.pylori, эрадикационная терапия не назначалась. Проводимая в стационаре антигеликобактерная терапия во всех случаях была представлена стандартной тройной терапией (ИПП+кларитромицин+амоксициллин). Дозировка назначенных антибактериальных препаратов соответствовала стандартной: кларитромицин по 500 мг 2 раза в сутки, амоксициллин - 1000 мг 2 раза в сутки. ИПП во всех случаях эрадикации были использованы в больших дозах (ежедневный двукратный прием), что в настоящее время рассматривается как одна из мер повышения эффрективности эрадикационной терапии. Продолжительность эрадикационной терапии Н. pylori в условиях стационара составила 7 суток, что соответствует Маастрихт-IV.

Во всех случаях обнаружения H.pylori в условиях гастроэнтерологического отделения пациентам было рекомендовано проведение повторной ЭГДС с биопсией с цитологическим исследованием на H.pylori через 1 месяц после эрадикационной терапии.

Заключение: в целом проводимую фрармакотерапию ЯБ в гастроэнтерологическом стационаре г.Саратова можно признать удовлетворительной, но необходимо усилить меры по выявлению и эрадикации H.pylori. 